\title{
The Pivotal Role of Knowledge Structure and Instructional Design in the Development of Teachers Teaching Mathematics to Students With Intellectual Disabilities
}

\author{
Chun-ip Fung \\ Circle and Square Academy Limited, Tsuen Wan, Hong Kong \\ Dichen Wang \\ The Education University of Hong Kong, Tai Po, Hong Kong
}

\begin{abstract}
During the last six years, we were engaged in professional development programme for mathematics teachers of special schools for students with intellectual disabilities (IDs). We were able to observe that mathematics teachers of students with IDs are left in a difficult situation where support in subject specific knowledge is lacking. Although the knowledge of the characteristics learners with special educational needs (SENs) as provided by psychology does help to open the door to successful teaching and learning of these students, how to teach subject content with constraints of students' disabilities is left open. This paper reports some qualitative data collected from the programme, which sorts out several key challenges in the field of mathematics education for students with IDs and demonstrates how the design science of mathematics education helps teachers to address teaching problems. Based on the data, we claim that: (a) teachers' ability to figure out milestones and intermediate learning states within a prolonged process of knowledge construction is crucial to teach students with IDs; and (b) using a design science approach to create carefully designed teaching units serves a dual role of providing teachers with teaching ideas as well as facilitating their understanding of mathematical knowledge structure.
\end{abstract}

Keywords: mathematics education for student with intellectual disabilities, teacher education, design science, knowledge structure

\section{Introduction}

During the past decades, an increasing number of studies have been carried out on mathematics education for children with special educational needs (SENs) (Myers, Jun, Brownell, \& Gagnon, 2015; Marita \& Hord, 2017). However, it was found that mathematical learning in this field was primarily studied from the behavioral, information processing, and medical perspectives, whereas considerably few focused on the teacher (Lambert \& Tan, 2016). A pressing need was acknowledged for providing more evidence with respect to what constitutes effective teacher training in this area (Allsopp \& Haley, 2015).

In the last six years, we were engaged in professional development programme (Teaching for

Chun-ip Fung, Ph.D., chief consultant, Circle and Square Academy Limited.

Dichen Wang, Ph.D. candidate, guest lecturer, Department of Mathematics and Information Technology, The Education University of Hong Kong. 
Mathematising, abbrev. TFM hereafter) in Hong Kong for mathematics teachers of special schools for students with intellectual disabilities (IDs). We were able to observe that mathematics teachers of students with IDs are left in a difficult situation where support in subject specific knowledge is lacking. This paper presents some qualitative data collected recently, which include observations in project meetings and teaching practice, semi-structured interviews with seven teacher participants, and teaching materials developed by the project. With reference to the bulk of data triangulated with existing literature, this paper sorts out several key challenges faced by teachers and demonstrates how TFM helps teachers address these challenges.

The structure of the paper is as follows. It begins with a brief introduction of the rationale of TFM, which is followed by a brief outline of the challenges of mathematics education for SEN students in Hong Kong. Afterwards, recent work of TFM on professional development of teachers of special schools is reported with emphasis put on the importance of clarifying knowledge structure and its impact on the design and implementation of teaching.

\section{The Rationale of TFM}

TFM was first introduced to Hong Kong in 1998. There are two important notions on which the project rests. In the first place, it is Hans Freudenthal's (1973) notion of “mathematics as a human activity,” which sees learning mathematics as simply an activity to re-invent mathematics. Under this philosophy, there is no passive learner, because a person is not considered as learning mathematics if he or she is not engaged in re-inventing the mathematics required to be learned. Instead, learning and teaching should be planned in order that learners can participate actively and gradually develop their understanding of the mathematical content by creating it themselves.

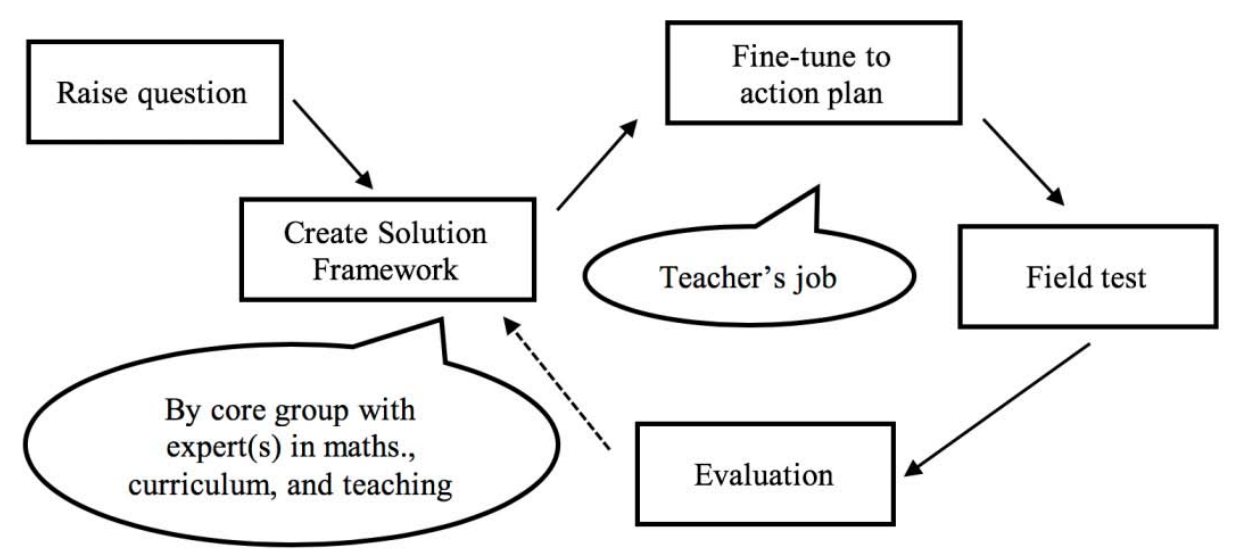

Figure 1. The action flow chart of TFM project (Translated by Fung, 2004).

The second, and equally important, is Erich Ch. Wittmann's (1984; 1995; 2001) notion of "mathematics education as a design science," under which carefully designed teaching units should form the core of study for researchers, teacher educators, and teachers. Specifically, teaching units serve to integrate knowledge of different fields, such as mathematics, psychology, and didactics into the practice of teaching.

Based on these two fundamental notions, TFM approaches most of the problems of teaching by developing teaching units. Once, a question of mathematics teaching is received, irrespective of whether it originates from general school or special schools, expertise from various related domains are pulled together to 
work out solution according to the development cycle described in Figure 1. Once, a solution framework (Which does not take into account characteristics of target student group) is generated, it will be passed to implementing teachers for fine-tuning to action plan in order to match local parameters (such as students' ability, classroom environment, available resources, etc.). Afterwards, it will be put to field test, which will be followed by an evaluation of the implementation process and result. Amendment of the solution framework or action plan will be made accordingly where appropriate. In this model, the researcher, or in Freudenthal's (1980) term, the "theoretician," works closely with the teacher to ensure that any solution implemented is both mathematically and didactically sound.

\section{An Example of a Teaching Unit}

Here is an example of a teaching unit developed to special school recently. Emily (pseudonym), a teacher teaching mathematics to students with mild grade IDs, said that there had been a long period of time that they had not taught division to their students. It was because that their students could not memorize multiplication table, she and her colleagues thus believed that their students were not ready to learn division.

Before any attempt to generate solution to teaching problem, TFM requires that an analysis of knowledge structure be done in advance. The concept of division is actually based on two different activities of dividing things - distributing things into groups of $d$ or distributing things into $d$ equal parts. The former is called "division by grouping where the number in each group is known", and the number of groups is to be determined. The latter is called "division by sharing where the number of groups is known”, and the number in each group is to be determined. Students could find out the unknowns of the two activities by grouping or sharing physical objects and then counting (see Figures 2 and 3). Completing these two activities does not need any prior knowledge of multiplication. Communication of result of division can be made by students in horizontal form as shown in Figure 4 without much difficulty. It is pretty clear that not capable of memorizing the multiplication table, or even not knowing multiplication at all, does not deprive students of the opportunity of carrying out division with the help of manipulatives, upon which a basic understanding of the concept of division can be acquired. Capability to use the multiplication table only enables the student to get the result of division by calculation.

After serious study of the mathematical structure behind, Emily conducted a teaching experiment to teach division to her students (12-16 years of age, with mild IDs). From the classroom observation, it was found that all students had acquired a basic understanding of the concept of division with the use of manipulatives. The next milestone for teaching is letting students re-invent the role of multiplication table in the calculation of division.

With the help of subject experts, Emily prepared a worksheet (see Figure 5) for students doing the grouping (or similarly, sharing) activity. The design secrets behind the worksheet are related students' grouping or sharing experience to the multiplication table (see the bolded numbers in Figure 5). During the teaching experiment, even students with just marginal experience of the multiplication table could well relate the entries to the multiplication facts listed in the multiplication table, hence recognizing the role of multiplication table in the calculation of division. At this stage, those with fluency in multiplication table could carry out column division on their own. For the rest, Emily supplied each with a multiplication table. In this case, students were free to consult it, so as to bypass their memory weakness. 
Grouping these 12 sweets into 3s
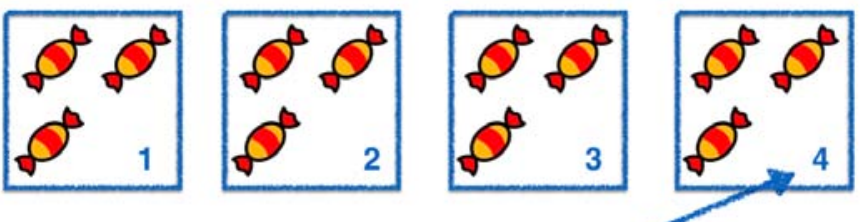

There are 4 groups.

Figure 2. Grouping activity.

Divide these 12 sweets equally between 3 groups.
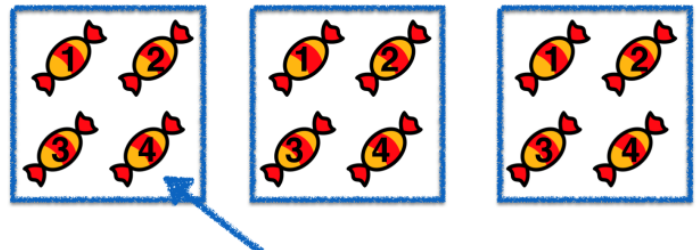

Each group gets 4 sweets.

Figure 3. Sharing activity.

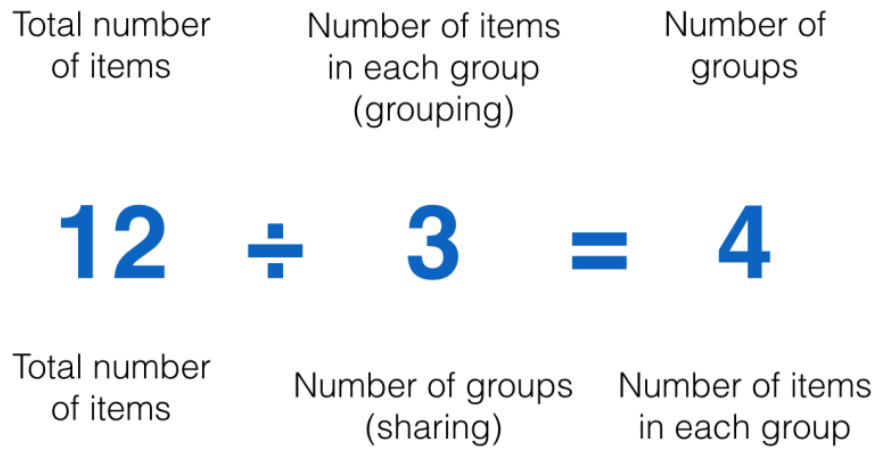

Figure 4. The meaning of " 12 divided by three is four."

Every $\mathbf{3}$ sweets are put in one bag, when $\mathbf{1}$ bag is packed, $\underline{\mathbf{3}}$ sweets are divided.

Every $\mathbf{3}$ sweets are put in one bag, when $\mathbf{2}$ bag is packed, $\underline{\mathbf{6}}$ sweets are divided.

Every $\mathbf{3}$ sweets are put in one bag, when $\underline{\mathbf{3}}$ bag is packed, $\underline{\mathbf{9}}$ sweets are divided.

Every $\mathbf{3}$ sweets are put in one bag, when $\underline{\mathbf{4}}$ bag is packed, $\underline{\mathbf{1 2}}$ sweets are divided.

Figure 5. Worksheet paving the way for students to discover the role of multiplication in the calculation of division (Translated from Chinese).

This teaching unit is an example of how TFM deals with the problem of teaching mathematics to students with IDs. It engages students in the process of re-inventing mathematics, and assists them to discover what they are supposed to learn. Serious analysis of knowledge structure enables Emily to distinguish the core, which is the part of teaching that should be kept intact at any cost, from the less important contents, which may well be 
detached without causing unmanageable impact on students' subsequent learning. This understanding gives Emily a good sense when selecting, adjusting, and omitting instructional contents, thereby making appropriate decisions to relieve students from unnecessary burden. The triadic relationship between knowledge structure, instructional design, and teaching practice will be described later in the paper.

\section{Contextual Challenges and the Work of TFM}

Latest figures indicate that $5.7 \%$ of the student population in Hong Kong has SENs (Finance Committee, 2014). Local policy put students with intellectual or physical disabilities in special schools while the rest receive inclusive education.

ID students studying in an inclusive classroom have to cope with the pace of teaching and learning that is generally tailored for non-ID students. Consequently, very often teachers tend to skip the kind of detailed and progressive teaching activities that are seen to be crucial to ID students' learning, but at the same time regarded by other students as developing too slowly and repetitively. Coupled with a mathematics curriculum, which is, on the average, two years ahead of the international median (Schmidt, 1996), most ID students under inclusive education are very often excluded from fruitful learning.

Teachers of special schools, on the contrary, are not tied tightly to any rigid curriculum requirement and are free to work out anything that is meaningful to their students. On the up side, devoted teachers have ample autonomy to explore and tailor their teaching to the SENs of their students. On the down side, lacking a clear demand for effective teaching relative to clear curriculum requirement allows poor teaching to prevail and propagate. Unlike general schools where a variety of textbooks and related resources are available, special schools suffer immense shortage of teaching resources. Given that most teachers follow, or are heavily influenced by, resources available, teachers of special school would easily find themselves being left in the unknown area of teaching. In response to the professional development need of these teachers, the government offers courses on catering for diverse learning needs, and in-depth training courses on supporting student with SEN (Education Bureau, 2015). Unfortunately, these courses do not address the mathematics-specific preparation of teaching for SEN students.

It was under such circumstances when TFM was introduced to teachers of special schools four years ago. The mission was to improve the quality of mathematics learning of students with SENs. During the period, we seek answers for the following questions:

1. If there is indeed something called mathematics-specific preparation of teaching for ID students, how does it look like?

2. What kind of research will support practice of mathematics teaching for ID students? And how?

The two authors of the paper were participant observers of the project. By interacting with teachers we studied, we were able to observe what information did teachers seek for during the project and how teachers' professional development happened. The first author played the role of both a teacher educator and a researcher. The second author served as a guide by pointing participating teachers to the knowledge and resource base of TFM. During the last four years, 49 teachers took part in the development program. Seven of them (see Table 1) were selected to reveal their own learning experience in how to teach mathematics to ID students and the characteristics of the experience they consider helpful to their work. The demographics of the seven interviewees are as follows (see Table 1): 
Table 1

\begin{tabular}{|c|c|c|c|}
\hline $\begin{array}{l}\text { Teacher } \\
\text { (Label) }\end{array}$ & Category of school & $\begin{array}{l}\text { Years of teaching in } \\
\text { special school }\end{array}$ & $\begin{array}{l}\text { Years of participating in } \\
\text { TFM }\end{array}$ \\
\hline $\mathrm{T} 1$ & Mild IDs & 9 & 1 \\
\hline $\mathrm{T} 2$ & Mild and moderate IDs & 23 & 2 \\
\hline T3 & Mild and moderate IDs & 20 & 1 \\
\hline $\mathrm{T} 4$ & Physical disabilities and IDs & 9 & 1 \\
\hline $\mathrm{T} 5$ & Mild IDs & 2 & 1 \\
\hline T6 & Moderate IDs & 25 & 2 \\
\hline $\mathrm{T} 7$ & Physical disabilities and IDs & 20 & 2 \\
\hline
\end{tabular}

Knowledge Structure and Its Impact

In the following section, we describe an instructional framework for the teaching unit—counting, addition, and subtraction - that we use to exemplify the importance of clarifying knowledge structure and its impact on the design and implementation of teaching.

\section{Counting, Addition, and Subtraction}

When teachers prepare to teach subtraction, more often than not, they think about subtraction. During our encounter with teachers, no matter teaching in a special classroom or an inclusive classroom, this phenomenon prevails. This is widely acceptable in the teaching profession, though far from being perfect. For many teachers, the aim of their lesson preparation is to make their lessons effective, which is almost unconditionally identified with "student can work out tasks according to the procedures told by the teacher." Under favorable conditions, this may happen and then the teacher will regard the lesson as being effective. However, if we look at it from the student's perspective, we would also like to ask, "Does this part of learning match well with previous experience?” Furthermore, "Does this part of learning effectively and efficiently pave the way for subsequent learning?” These questions lead us to consider what Bruner (1977) concluded in his classic work that "the curriculum of a subject should be determined by the most fundamental understanding that can be achieved of the underlying principles that give structure to that subject” (p. 31). In what follows, we try to outline, albeit very briefly, a knowledge structure for teaching counting, addition, and subtraction, spanning from the most basic level of counting to the highly symbolic level of column subtraction of two-digit numbers. It forms the foundation for teacher development described in this paper.

Before a child can run into arithmetic, he or she must first know how to label an amount with a name. In principle, we need infinitely many different names to correspond to infinitely many different amounts. This creates great trouble if mathematics needs to deal with arbitrarily large amounts. Here comes the need to have a structure-a structure to enable us to label great many different amounts by using just a small number of symbols. The Hindu-Arabic numeration system we use today is one solution to such problem. It requires ten different numerals $(0,1,2,3,4,5,6,7,8$, and 9), a base-10 place value system, and a positional recording convention. Two obvious pre-requisites for applying such system are: (a) the ability to recognize the symbols for the 10 numerals, and be able to arrange them in ascending (and descending) order of magnitude; and (b) the ability to think and act based on different units, such as 1's, 10's, 100's, etc.

Going from 1 to 9, students are confronted with nine different symbols. They need to learn the actual amount (in terms of number of certain objects), the sound (as read aloud), and the written text corresponding to 
each of them. This can be demanding for young children, especially those with IDs. The activity that pulls all these together is called counting. According to Gelman and Gallistel (1978), counting "involves the coordinated use of several components: noticing the items in an array one after another; pairing each noticed item with a number name; using a conventional list of number names in the conventional order; and recognizing that the last name used represent the numerosity of the array" (p. 73), and encompasses the skillful application of the following principles: The One-One Principle which says that objects are partitioned into the to be counted group and the counted group and that the element of the former is moved to the latter one at a time; The Stable-Order Principle which says that a counting person must be able to use the same sequence of tags to correspond to items to be counted; The Cardinal Principle which says that the tag used for the last one counted is the cardinal number of the sets of objects counted; The Abstraction Principle which states that the preceding principles can be applied to both physical and non-physical objects; and lastly, The Order-Irrelevance Principle which says that the counting result is independent of the order of objects being counted (Gelman \& Gallistel, 1978, p. 73).

For students with IDs at moderate to severe grade, learning to count from 1 to 10 is a process that can be very long and painstaking. They have difficulties in: (a) remembering the sequence of sounds; (b) remembering the sequence of symbols; (c) matching the sequence of sounds with the sequence of symbols; and (d) matching the two sequences with the number of objects they see. In order to help them overcome obstacles during memorization process, the Louis Program Training Centre (Retrieved from http://www.lp.org.hk/e_index.htm) has developed a program of home training under which students start learning small numbers through repetitive counting tasks that incorporate progressive minor variations. In the counting book used, we find objects to be counted. Their corresponding generic representation using circles and number symbols (see Figure 6). Page after page, changes incorporated range from positions of objects, characteristics of objects, to hint level concerning the number symbols. The idea was adopted by some teachers of special school who turned the counting book into an electronic version to be used on interactive whiteboard. Its obvious advantage over the printed book is that clues and hints for the sound sequence can also be included.
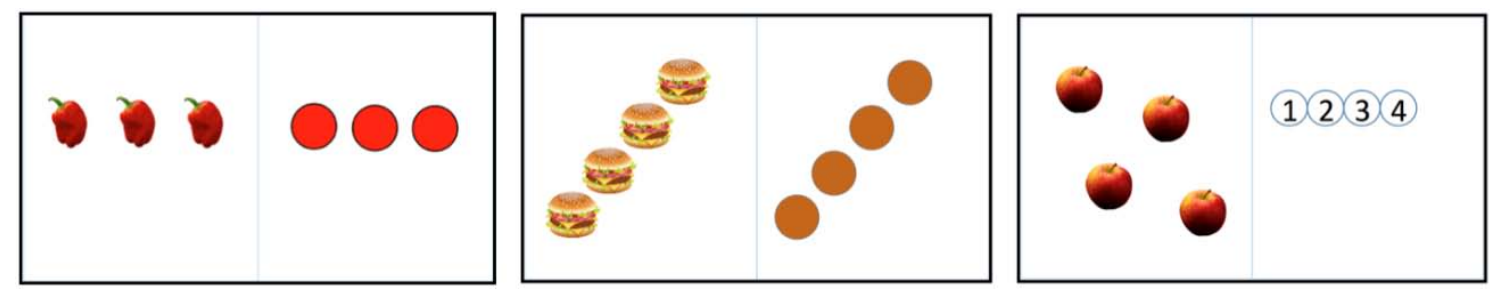

Figure 6. Design of counting tasks.

Achievement 1. Student knows how to count up to $N$, and hence is able to:

(a) determine any number of objects not exceeding $N$ by counting;

(b) get any number of objects not exceeding $N$ by counting.

Once students can count up to a certain number $N$ (which could be any not-so-small number), the concept of addition (put together) and subtraction (taken away) can be studied. To find $a+b$, all one needs to do is to first count and get $a$ counters, then count and get $b$ counters, and finally putting them together and count to get the sum. To find $a-b$, one could first count and get $a$ counters, then count and remove $b$ counters, and finally count the remaining to get the difference. These processes can be regarded as the basic principle of addition and subtraction. If a person can remember the positive integer sequence up to $N$, he or she can perform addition and 
subtraction within the range by counting counters alone. Once the skill is further improved to include counting pictures (or any static things that cannot be moved around), we arrive at another achievement milestone.

Achievement 2. Within the counting limit $N$, given $a$ and $b$, student knows how to get $a+b$, and $a-b$ by counting counters or pictures.

Based on fluency of counting to $N$, student could develop techniques of counting up or down from any arbitrary number within the range. These techniques enable the student to get $a+b$, by using just $b$ counters only. Counting up begins at $a$ and for each of the $b$ counters counted, the student counts up one number. The process ends when all the $b$ counters are counted, and the last-named number is $a+b$. Doing it the reverse way, the students can get $a-b$, by using again just $b$ counters. Counting down begins at $a$ and for each of the $b$ counters counted, the student counts down one number. The process ends when all the $b$ counters are counted, and the last-named number is $a-b$.

When these techniques are applied to a restricted context where the number of counters $(b)$ is replaced by student's ten fingers, and the student is capable of recognizing quickly any number (not exceeding 10) of fingers erecting, the student then obtains a convenient method of calculation, called "finger-counting."

Achievement 3. In expressions of the form $a \pm b=c$, where all three numbers do not exceed $N, a$ is given, and $b \leq 10$, the student can determine any one of $b$ and $c$ once the other is known.

When student's counting limit becomes larger over time, counting large number of objects is possible and can be accomplished in a speedy manner through counting by 2, 5, or 10. In particular, counting by 10 has its special significance on extending the naming and recording of numbers from using just a sequence of isolated names, to a system where the 10 Hindu-Arabic numerals are structurally applied to represent practically infinitely many numbers.

Achievement 4. By grouping into powers of 10 (1, 10, 100, etc.), and restricting that any group of the same size cannot have more than 9 , any number can be recorded uniquely by using just the 10 numerals, filling the digits from right to left which successively corresponds to the number of 1's, 10's, 100's, etc. occurring.

The numeration system follows from Achievement 4 is what we called "the base" -10 positional numeration system. Essentially, it is a number recording system that registers the number (not exceeding 9) of each power of 10 by column, starting from the unit column on the right. Addition and subtraction can be done by column, with cross-column exchange activity inserted where appropriate. In addition, when it occurs that a column sum exceeds 9, carrying forward to a higher power of 10 is necessary because each digit can only register up to 9. Similarly, in subtraction, when there is insufficient number of a certain power of 10 to be taken away, borrowing from the next higher power column is necessary. Irrespective of whether carrying or borrowing is involved, calculation within a column takes the form $a \pm b$, with $a \leq 18, b \leq 9$. It follows that calculation within a column can be completed based on Achievement 3 with $N$ being 20. In short, addition/subtraction of multi-digit numbers is essentially repeated application of Achievement 3 (with $N$ being 20) to each of the digits.

\section{Impacts of Clarifying Knowledge Structure on Teaching}

Next, we describe some issues that emerged in our observation and interview data, thereby, exemplifying the potential of the knowledge structure in helping teachers design and carry out teaching activity.

The knowledge structure is useful for teachers for several reasons. First, it helps teacher articulate the learning objectives of students. Almost all the interviewed teachers mentioned that they felt very challenging to 
set appropriate learning objectives and tasks, and $\mathrm{T} 1$ gave us an explanation:

In general school curriculum, multiplication and division are taught in Grade 2 and Grade 3, but a student with moderate IDs in special educational school only starts to learn this topic in his 12th year of schooling. It means he or she spends 12 years but only learns the content that normal students spend two or three years learning. Regarding the same content but increased class hours, how to break down the learning content into small objectives? This is worth thinking, but beyond my limited mathematics knowledge.

Four teachers (T3, T4, T6, and T7) felt that some topics in mathematics are "hard to teach". Both T3 and T7 mentioned "counting 1-10" as an example. T7 explained:

These topics are so easy that people could not even figure out what to teach! However, students with moderate IDs spend years on these topics. What to teach and how to teach these topics are difficult questions for teachers.

T6 shared their experience in preparing and teaching these "hard" topics. T6 said when she does not have idea about how to teach a topic, she always "search different activities relating to this topic" from various sources. Very often, she used them as the content to be covered during class time without knowing the value and importance of those activities. T7 provided an example about counting and illustrated how TFM helped her clarify the objectives of learning activities. She said:

[...] some students in my class have difficulties in counting. So, I let them sing counting 1-10 song every lesson, hoping that it could help them learn counting [...]. However, after participating in TFM, I knew singing number song simply help students remember the sequence of sounds, and other learning activities need to be included to help students match the sequence of sounds with the sequence of symbols, or the sequences with the number of objects they see [...]. Had I not studied the knowledge structure, I might never have found what important parts were missing in my teaching.

Second, knowledge structure helps teacher understand the connection of knowledge. T4, T5, and T6 mentioned this point during the interview. T6 shared her experience in teaching counting and addition:

TFM helped me find out the teaching gaps between the two topics—counting and addition. [...] I used to think that the value of counting by 2, 5, and 10 is only to train students to count more conveniently. But now, I know counting by 10 is actually paving way for students learning carrying in addition. If they did not learn counting by 10, they will have an ambiguous concept of carrying. [...] When we were learning carrying during addition, we may not have to learn counting by 10 first. It is because we have high level of abstract thinking, we could jump this step (counting by 10) to carrying. However, it is not the case when it comes to children with IDs. Especially for children with weak abstract thinking ability, they have to learn concepts through a great amount of activities using manipulatives. After understanding the importance of pre-knowledge of counting by 10 when learning carrying in addition, I provided a lot of activities for my students to learn it. I provide different kinds of objects for my students to count by 10 and let them turn those objects into a packet to represent "carrying" when the number of objects adds up to 10 . When the number of objects is more than 10 , my students, such as Ka (one of her students), will not put all the objects into a bag. On the contrary, if they find the number of objects in the bag is more than 10, they will take away the surplus part. But students, who do not learning counting by 10, would not do so. They just copy their teachers' action— put objects into the bags.

Third, knowing the knowledge structure of topics would also help teacher develop instructional design. For example, when teachers have a deep understanding about counting, they are more capable of designing appropriate activities for students. In TFM lesson preparation meeting, teachers could identify the nature and purpose of the activities - whether an activity is matching the sound to the symbol or matching the sound to the amount, whether an activity is training the sequence of sound or training the sequence with the numbers. With the knowledge about counting, teachers were clear about what learning experience they are providing to their students during lesson. Based on that, they optimize the original matching activity (see Figure 7) in to a version 
for students with more severe IDs. They did this by breaking down the original activity into three steps (see Figure 8), which uses a "transition card" for students to easily understand their learning objective. It is because students with moderate to severe developmental disabilities may have difficulty in comprehending teachers' instruction. A transition card is provided to bridge the understanding of the symbol " 3 " and the amount " 3 ". Class observation shows that the "transition card" did help some students with low ability.

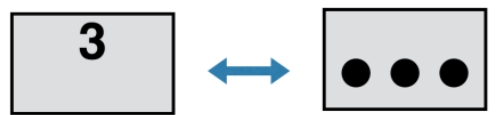

Figure 7. Matching the card with 3 counters to the card with the symbol "3”.

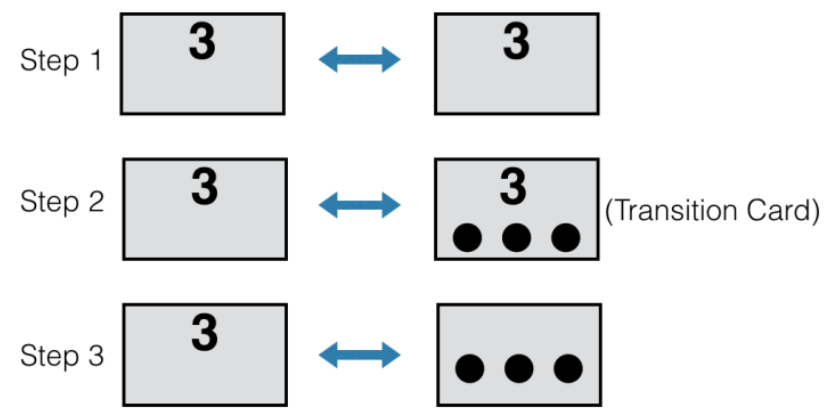

Figure 8. Steps to help students match the symbol "3" with its corresponding amount.
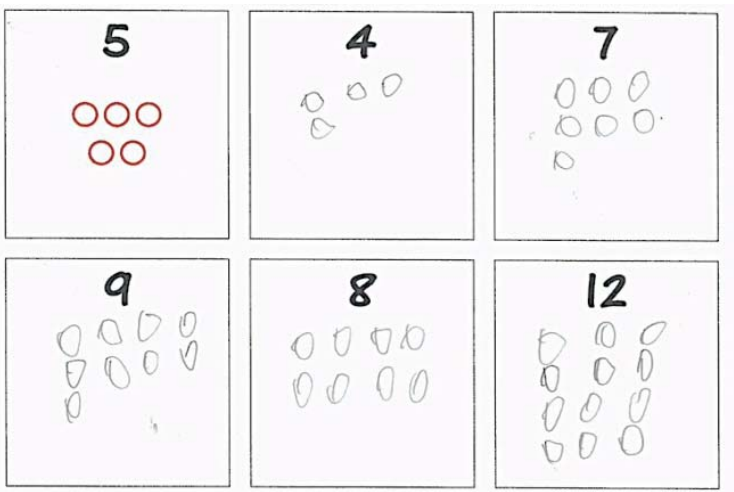

Figure 9. Worksheets for practice giving number of objects by counting.

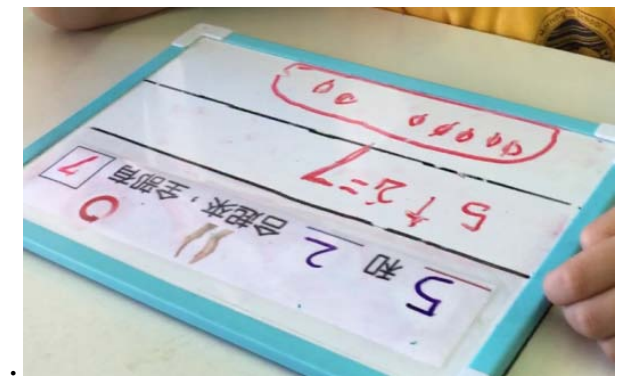

Figure 10. Student's work of calculating addition by counting.

With an understanding of the knowledge structure of addition and subtraction, teachers recognize that before learning addition and subtraction, student must be capable of getting any number of objects by counting. Therefore, teachers designed a worksheet (see Figure 9), which paves the way for further learning in addition, 
and subtraction (see Figures 10 and 11). They first provide some physical objects for students to do the addition and subjection by counting. Second, they asked students to draw circles to replace the physical objects. Three teachers who have implemented this design reported that after these activities, their students had good command of the concepts of addition and subtraction. T6 said,

When they saw “-”, they know that they should take away or cross some objects. When they saw “+”, they know that they should count all the objects. They could distinguish the two operations clearly.

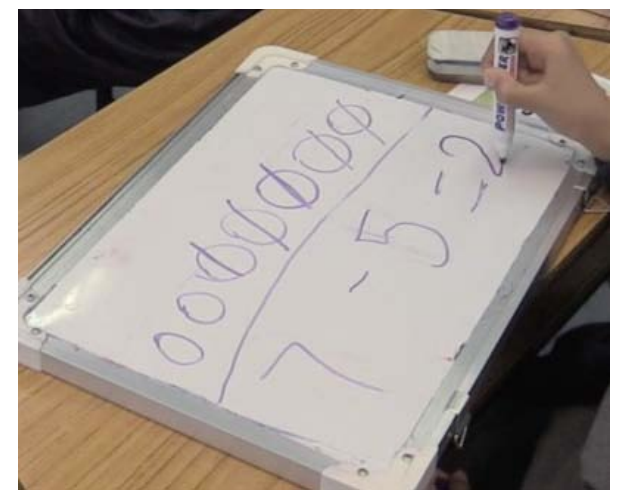

Figure 11. Student's work of calculating subtraction by counting.

T7 also mentioned that before participating in TFM, she used to have little confidence in designing learning activity, because she "does not know whether the activity is mathematically correct or not". However, after learning TFM, she felt more confident in mathematics. She shared one experience of criticizing her colleague's idea of using peculiar drawing (see Figure 12) to teach students subtraction. She said,

When I saw the drawing, I immediately realized it is not appropriate for explaining subtraction. The drawing cannot help students develop a sense of "taking away". Instead, students may misunderstand that what the drawing shows is five circles. If the teacher uses this drawing to illustrate subtraction, students probably could not acquire any conceptual understanding of it. Instead, they just imitate what the teacher does during lesson.

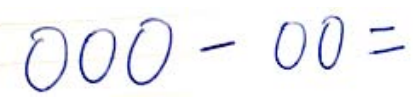

Figure 12. A drawing not appropriate for explaining subtraction.

T5 also shared her experience about how the knowledge structure of subtraction helps her adjust learning objective and designing learning activity to students at different levels. She used to believe that "the skill of counting down is a pre-requisite to learning subtraction.” However, after consulting TFM advisor, she understood "counting down is just one of the strategies in doing subtraction." Learning subtraction involves both an understanding of the concept, and various means to get the difference. The core message that students should know about subtraction is that it is "an operation representing taking away some objects and finding the number of remaining objects.” Therefore, she adjusted the teaching objective and students' learning activities. She categorized her students into three groups according to their pre-knowledge of counting:

The highest ability group who had the ability of counting down will learn calculating subtraction by counting down. The middle ability group who could draw correct number of circles will learn doing subtraction by drawing and crossing circles. For those with low ability, she provides them with the physical objects, and teaches them taking away the specified number of objects and counting out the remaining objects. 
T5 also mentioned that she "used to require all students to learn the method of counting down," and now she only "requires students with high enough ability to learn the counting down strategy to calculate subtraction."

When teachers have a good understanding of a mathematical concept and the knowledge structure behind it, they have the ability to distinguish whether a piece of knowledge or skill is a minor teaching point or belongs to the core. This is very important in mathematics education for students with special educational needs because teachers have to face the challenges of students' disability and diversity. In the absence of a set of objectives suitable for all students, teachers have to make decision about which content is fundamental and have great impact on students' further learning, and which is not.

\section{Conclusions}

This paper intends to consolidate insights from the TFM professional development program for special-school teachers, hoping to shed light on the mathematical preparation needed for teaching students with special educational needs. We conclude by answering the two questions raised before:

\section{If There is Indeed Something Called Mathematics-Specific Preparation of Teaching for ID Students, How Does It Look Like?}

Teachers need supports in mathematics. This kind of mathematics does not originate from the mathematics commonly taught at university level, but rather from a re-invention perspective- - How mathematics knowledge could be constructed and developed at students' level. In order to tailor teaching objectives and activities to students with ID, teachers' ability to figure out milestones and intermediate learning states within a prolonged process of knowledge construction is crucial. Without thorough deliberation and serious study of knowledge structure, such ability can hardly be developed among teachers.

\section{What Kind of Research Will Support Practice of Mathematics Teaching for ID Students? And How?}

Our findings suggest that design research is the answer. Design research is a kind of research that aims at developing a local instruction theory with two objectives. One is to study students' learning trajectory of a mathematical topic and the other is to study the means to support that learning process (Gravemeijer \& van Eerde, 2009). The main pre-condition for designing effective learning trajectory is, according to previous discussion, an in-depth analysis of knowledge structure. This is especially the case for mathematics where new knowledge is often derived from the old. Could teachers do the job themselves? Our interviewed data unambiguously confirmed the otherwise. If teachers alone cannot possibly do the job, we need contribution from, in Freudenthal's (1980) term, a theoretician:

What the theoretician in the team should be able to do on the ground of his background knowledge is to react to the phenomena in the field, connecting them, placing them into larger frames without appealing to, let alone, settling on, pre-established theories. For instance, he should be able to recognize common elements in subject matter or presentation as a signal that promises success or failure even when no theory exists that in a certain situation allows the deduction of this result. (p. 177)

The theoretician, being someone well-trained in both mathematics and its teaching, takes up the tasks of clarifying the knowledge structure and suggesting feasible learning trajectories. While all these can be done without much understanding of student characteristics, further work is needed to turn them into detailed instructional designs ready for implementation at specific classrooms. At this point, teacher development is 
needed to ensure teachers actually carrying out the teaching can understand the knowledge structure upon which teaching is being designed, and the rationale behind the learning trajectory adopted, thereby fill in the details of the action plan entailed. The study and design of teaching units, thus, becomes the focal point for research and teacher development to happen (Wittmann, 1984; 1995).

\section{References}

Allsopp, D. H., \& Haley, K. C. (2015). A synthesis of research on teacher education, mathematics, and students with learning disabilities. Learning Disabilities-A Contemporary Journal, 13(2), 177-206.

Bruner, J. S. (1977). The process of education. Cambridge, MA: Harvard University Press. http://dx.doi.org/10.2307/j.ctvk12qst

Education Bureau. (2015, July 10). Teacher professional development on catering for students with special educational needs (Education Bureau Circular No. 12/2015). Archives of the Circulars of Education Bureau Council, Hong Kong. Retrieved May 14, 2017, from http://applications.edb.gov.hk/circular/upload/EDBC/EDBC15012E.pdf

Finance Committee. (2014, January 31). The 20th meeting of finance committee on examining the estimates of expenditure 2014-2015. Finance Committee Papers (EDB-2-c1.docx). Archives of the Papers of Legislative Council, Hong Kong. Retrieved May 14, 2017, from http://www.legco.gov.hk/yr13-14/chinese/fc/fc/w_q/edb-c.pdf

Freudenthal, H. (1973). Mathematics as an educational task. Dordrecht, Netherlands: Reidel. Retrieved from http://dx.doi.org/10.1007/978-94-010-2903-2

Freudenthal, H. (1980). Weeding and sowing: Preface to a science of mathematical education. Dordrecht, Netherlands: Springer.

Fung, C. I. (2004). Teaching for mathematising: Theory, practice, and prospect. In K. M. Tang, K. L. Wong, M. S. Lee, and N. C. Mok (Eds.), Proceedings of Hong Kong Mathematics Education Conference 2004 (pp. 78-88). Hong Kong: Hong Kong Association for Mathematics Education. (in Chinese)

Gelman, R., \& Gallistel, C. R. (1978). The child's understanding of number. Cambridge, MA: Harvard University Press.

Gravemeijer, K., \& van Eerde, D. (2009). Design research as a means for building a knowledge base for teachers and teaching in mathematics education. Elementary School Journal, 109(5), 510-524. http://dx.doi.org/10.1086/596999

Lambert, R., \& Tan, P. (2016). Disability and mathematics: Theorizing the research divide between special education and mathematics. In Proceedings of the Psychology of Mathematics \& Education of North America Conference (pp. 1057-1063). Tucson, AZ.

Marita, S., \& Hord, C. (2017). Review of mathematics interventions for secondary students with learning disabilities. Learning Disability Quarterly, 40(1), 29-40. http://dx.doi.org/10.1177/0731948716657495

Myers, J. A., Jun, W., Brownell, M. T., \& Gagnon, J. C. (2015). Mathematics interventions for students with learning disabilities (LD) in secondary school: A review of the literature. Learning Disabilities-A Contemporary Journal, 13(2), 207-235.

Schmidt, W. H. (1996). Characterizing pedagogical flow: An investigation of mathematics and science teaching in six countries. Dordrecht, Netherlands: Kluwer Academic Publishers.

Wittmann, E. (1984). Teaching units as the integrating core of mathematics education. Educational Studies in Mathematics, 15(1), 25-36. http://dx.doi.org/10.1007/BF00380437

Wittmann, E. C. (1995). Mathematics education as a “design science”. Educational Studies in Mathematics, 29(4), 355-374. http://dx.doi.org/10.1007/BF01273911

Wittmann, E. C. (2001). Developing mathematics education in a systemic process. Educational Studies in Mathematics, 48(1), $1-20$. 